\title{
Graphic Narratives of Open Scholarship
}

\author{
Giulia Forsythe \\ Centre for Pedagogical Innovation \\ Brock University
}

\section{Correspondence:}

Giulia Forsythe

gforsythe [at] brocku.ca

\begin{abstract}
Public engagement and collaboration through networked practices-known as networked participatory scholarship (NPS) -may influence academic culture to "support, amplify, and transform scholarship" (Veletsianos \& Kimmons, 2012, p. 768). This study examined the open online scholarly community \#FemEdTech as it engages in NPS to create, collect, and curate value statements to generate iterative codes of conduct. Contents of tweets that include the Twitter hashtags \#FemEdTech and \#FemEdTechValues were thematized. The findings are represented as a visual metaphor of a map charting the fluid nature between policy design and implementation, described as the \#FemEdTech Cartography. This collaborative policy creation can serve as a model to shift academic culture towards more socially just practices using open scholarship to address the pressing issues of our time.
\end{abstract}

Keywords: open scholarship, open educational resources, open access, academic culture, policy 
In five minutes of lightning insight, I will attempt to answer the research question: how can policy shift academic culture towards more democratic, equitable, globally-just practices?

To do this, I looked at networked participatory scholarship (Veletsianos \& Kimmons, 2012) and their "webs of significance specific to open networks" (Stewart, 2015, p. 34) in power differentiated communities and their situated knowledges (Haraway, 1988).

Specifically, I took a deep dive into the open scholarly community, \#FemEdTech, using a bricolage of tweet and blog content analysis (Stewart, 2017), arts-based research, and material semiotics (Rosiek, 2017). More specifically, I have drawn "comics the scholarly way" (Kuttner, Sousanis, \& Weaver-Hightower, 2017) by engaging in comics-based research.

Participants will join me on an epic journey through the \#FemEdTech cartographies (see Figure 1). We will perambulate across ecological metaphors: rivers, forests; mountains as we encounter danger metaphors: Internet orcs, trolls (see Figure 2), and dragons. We will forge new paths to discover hidden hero stories, carelessly erased through negligence. More deeply, we will expose and retell those stories that have been historically systemically excluded through colonialism, capitalism, misogyny, and racism.

Now is the time for telling of these new stories, re-remembering of old ones almost forgotten through the nourishment of diverse ecosystems, and assembling new futures.

\section{Figure 1}

\section{\#FemEdTech Cartographies}

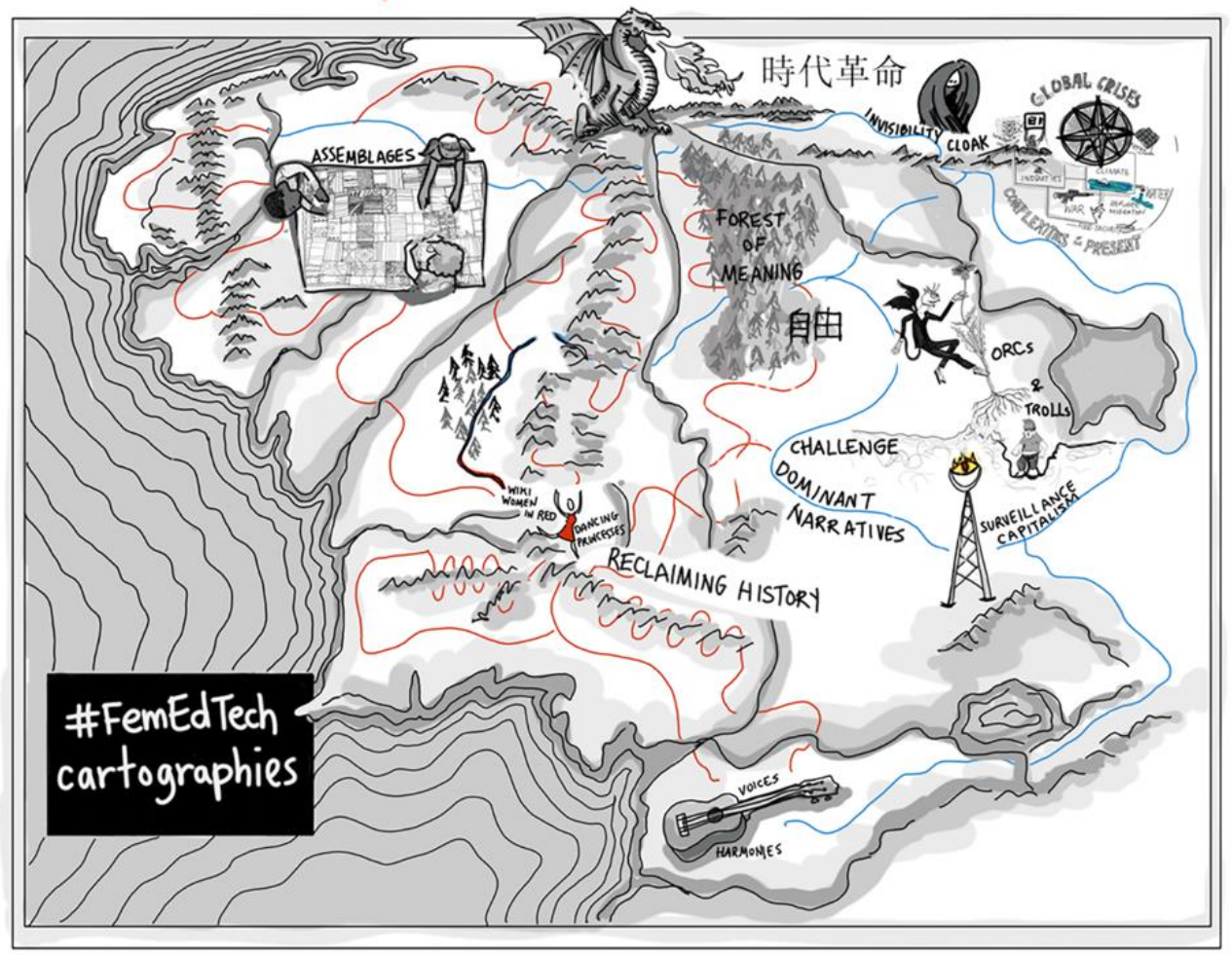




\section{Figure 2}

Internet Troll and Orc Modifying Paths That Do Not Conform With Their Views

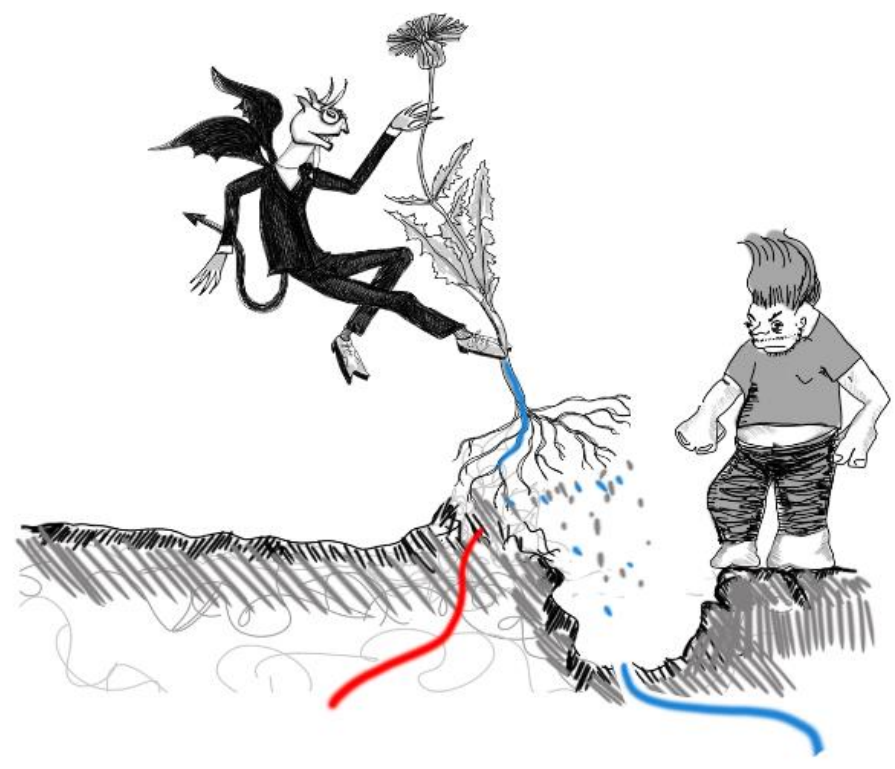

\section{Author's Contributions}

This proposal was created while the author was in the process of completing the Major Research Paper (MRP) in partial fulfillment of the requirements for the degree of Master of Education.

\section{Open Researcher and Contributor Identifier (ORCID)}

Giulia Forsythe (iD https://orcid.org/0000-0001-9669-9706

\section{Acknowledgements}

The author would like to thank her supervisor, Dr. Rahul Kumar and the \#FemEdTech community, specifically Frances Bell, Louise Drum, Helen Beetham, and Lou Mycroft for their generous scholarship, collegiality, and friendship.

\section{Ethics Statement}

A formal application detailing the manner in which data was to be collected, stored, and analyzed was submitted and a formal exemption letter was issued by the Research Ethics Board (REB) as a form of clearance, as per Brock University REB file \#19-268.

\section{Conflict of Interest}

The author does not declare any conflict of interest. 


\section{Data Availability Statement}

Details and links to the data sources can be found within the published Major Research Paper in the Brock University Digital Repository.

\section{References}

Haraway, D. (1988). Situated knowledges: The science question in feminism and the privilege of partial perspective. Feminist Studies, 14(3), 575-599. https://doi.org/10.2307/3178066

Kuttner, P., Sousanis, N., \& Weaver-Hightower, M. (2017). How to draw comics the scholarly way. In P. Leavey (Ed.), Handbook of arts-based research (pp. 396-423). Guilford Publications.

Rosiek, J. (2017). Art, agency, and ethics in research: How the new materialisms will require and transform arts-based research. In P. Leavey (Ed.), Handbook of arts-based research (pp. 632-648). Guilford Publications.

Stewart, B. E. (2015). Scholarship in abundance: Influence, engagement, and attention in scholarly networks. [Unpublished doctoral dissertation]. University of Prince Edward Island. http://bonstewart.com/Scholarship in Abundance.pdf

Stewart, B. (2016). Twitter as method: Using Twitter as a tool to conduct research. In L. Sloan \& A. Quan-Haase (Eds.), The SAGE handbook of social media research methods (pp. 251265). https://doi.org/10.4135/9781473983847

Veletsianos, G., \& Kimmons, R. (2012). Networked participatory scholarship: Emergent technocultural pressures toward open and digital scholarship in online networks. Computers \& Education, 58(2), 766-774. https://doi.org/10.1016/i.compedu.2011.10.001 